\title{
MULTIMEDIA
}

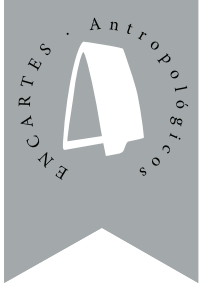

\section{EL HILO DE LA MEMORIA}

THE THREADS OF MEMORY

\section{Mariana Rivera*}

Link para el vídeo:

https://vimeo.com/151735928

Resumen: Durante tres meses se realizó un recorrido por México con la exposición titulada Tejer con el hilo de la memoria: puntadas de dignidad en medio de la guerra; en ella se mostró el trabajo de un colectivo de tejedoras colombianas conformado por mujeres sobrevivientes del conflicto armado. A través del tejido han contado sus historias, denunciando las injusticias y la violencia que han sufrido. La exposición fue compartida con grupos de tejedoras de la ciudad de México, Guerrero y Chiapas; a la par, se impartieron talleres de tejido y memoria y se realizó una muestra audiovisual. El hilo de la memoria es un documental que sigue el recorrido de la exposición en su viaje por México, reflexiona sobre los puentes que se tejen entre la creación colectiva, la creatividad y el potencial transformador de la realidad que tienen los espacios compartidos para contar y tejer.

Palabras claves: antropología visual, tejido, memoria, narrativas textiles y metodologías creativas.

\section{THE THREADS OF MEMORY}

Abstract: An exhibition entitled Tejer con el hilo de la memoria: puntadas de dignidad en medio de la guerra (Knitting the Threads of Memory: Stitches of Dignity, Surrounded by War) toured Mexico over the course of three months and presented work by a collective of Colombian knitters, all women who had survived experiences of

* Dirección de Etnología y Antropología Social (DEAS-INAH).

ISSN: 2594-2999, Bajo licencia Creative Commons

ENCARTES antropológicos 2 • septiembre 2018-marzo 2019, pp. 218-223

Recepción: 28 de abril de 2017 • Aceptación: 7 de septiembre de 2017

http://www.encartesantropologicos.mx

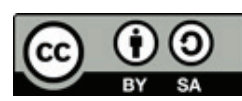


armed conflict. Through knitting they have both recounted their stories and denounced the injustices and violence they have suffered. The show was presented to knitters' groups in Mexico City and the states of Chiapas and Guerrero; there were concurrent knitting and memory workshops as well as an audiovisual presentation. El hilo de la memoria is a documentary that follows the show's Mexico tour in a reflection on the links that are woven between collective creation, creativity and the transformative potential of the reality inside spaces we share for knitting and storytelling.

Keywords: visual anthropology, knitting, memory, textile narratives, creative methodologies.

$\mathrm{T}$

ejer no es sólo un pasatiempo, ni una actividad doméstica realizada por mujeres; es un reflejo del pensamiento, un mantra repetitivo que invita a la abstracción y al descubrimiento de sí mismo.

Tejer es una forma de escritura, un lenguaje, un instrumento que refleja la identidad del creador; es un artilugio de comunicación, una actividad que libera, sana y hace que la concepción del tiempo sea otra.

El hilo de la memoria es un documental que forma parte de una serie de cinco cortometrajes que realicé en el marco de mi tesis doctoral, titulada "Tejer y resistir. Etnografías audiovisuales y narrativas textiles entre tejedoras amuzgas en el estado de Guerrero y tejedoras por la memoria en Colombia". Dicha investigación se centró en los diálogos establecidos entre la antropología visual, la memoria y los procesos de creación colectiva, fusionando así diversas perspectivas que me permitieron comprender el tejido, entre otras cosas, como una metáfora que ha servido para explicar el entorno social y para dar sentido al mundo. Esta metáfora se ha utilizado, por ejemplo, entre antropólogos y sociólogos para explicar el entramado de relaciones que los individuos tejen para formar redes; también es utilizado en la biología para hablar del tejido como el conjunto organizado de células. Incluso en algunas lenguas el concepto de tejer es análogo al acto de pensar, como sucede entre los indios kogis de Colombia. En mi caso, entender el tejido no sólo como antropóloga sino también como tejedora fue doblemente revelador, porque me permitió concebirlo como una actividad que propicia la creación de un sentido comunitario, para posteriormente dignificar y empoderar a sus ejecutantes. Asímismo, permite fortalecer lazos solidarios y deja ver, más allá de la metáfora, cómo se va hilando el tejido social. 
Para comprender este enfoque fue necesario saber tejer, porque sólo a través de la experiencia con el cuerpo, experimentando los efectos del tejido sobre nuestro cerebro y nuestras emociones, se puede comprender cómo esta actividad repercute también en lo social. Es necesario tomar un hilo, un ganchillo, un telar o unas agujas y comenzar a tejer para dejarse envolver por el singular efecto del tejido sobre nuestro cuerpo y nuestro entorno; por ello, partí de mi experiencia como tejedora, experimentando con mi cuerpo los efectos sanadores y reflexivos que me brindaba esta actividad, especialmente cuando la llevaba a cabo junto a otras personas.

Me di cuenta que tejer en colectivo genera espacios donde no sólo se tejen hilos: se tejen historias, afectos, ideas, resistencias y soluciones. Se plantean escenarios, problemas sociales y necesidades individuales. El tejido compone un espacio de socialización donde la creatividad emerge y da lugar a la reflexión para incidir sobre lo político-público; es decir, brinda una posibilidad de enunciar y visibilizar el dolor ajeno para volverse sensible ante él, y por supuesto, desarrollar la capacidad de resiliencia.

Uno de los objetivos fue incentivar la capacidad reflexiva, tanto personal como colectiva, por parte de las tejedoras amuzgas, para considerar los textiles en su dimensión simbólica, narrativa, afectiva y creativa. El aporte de este abordaje fue brindar la posibilidad de generar pensamientos e ideas compartidas en torno al tejido y su capacidad transformadora.

Esta inquietud, en principio personal, se transformó en una vivencia colectiva y se convirtió en una investigación colaborativa donde se integraron otros conocimientos de orden afectivo, sensóreo-corporal, narrativo, manual y creativo que comprende el trabajo de la tejeduría.

La propuesta metodológica estuvo basada en la impartición de talleres, una exposición y la realización de cinco videodocumentales. Estas estrategias se convirtieron en una forma alternativa de hacer etnografía de corte experimental para comprender el trabajo textil en distintos contextos, y también para tender lazos y redes entre tejedoras de otras latitudes y compartir, a través de sus tejidos, sus propios procesos sociales como mujeres y tejedoras organizadas en cooperativas textiles. Ése fue el caso del intercambio que propicié entre tejedoras de Chiapas, Guerrero y Colombia y que dio lugar a la creación del documental El hilo de la memoria.

Impulsé, junto a mi colega colombiana Isabel González, un intercambio de trabajos textiles entre las tejedoras de Colombia y algunos colectivos de tejedoras en México, de manera especial se estableció el vínculo 
con las tejedoras amuzgas en el estado de Guerrero, con quienes realicé trabajo de campo. Sin embargo, también se extendió el intercambio con experiencias de tejedoras urbanas como el colectivo Bordando por la Paz y la Memoria: una víctima un pañuelo, así como en la Escuela de Artes y Oficios Emiliano Zapata, en la colonia Santo Domingo de la ciudad de México. Por otro lado, hubo también un importante intercambio con un grupo de tejedoras de Zinacantán en Chiapas, quienes conforman el colectivo Malacate Taller Experimental Textil.

La experiencia cristalizada en el presente documental consistió en montar una exposición titulada Tejer con el hilo de la memoria: puntadas de dignidad en medio de la guerra, en la que se mostró el trabajo del colectivo Costurero por la memoria de Sonsón, de Colombia, conformado por mujeres sobrevivientes del conflicto armado, quienes a través de sus tejidos comenzaron a denunciar las injusticias y las historias de violencia y lograron hacerlas visibles al utilizar el tejido como soporte narrativo.

Durante tres meses, de noviembre del 2014 a enero del 2015, la exposición recorrió los espacios antes mencionados, con la idea de socializar la experiencia a otros colectivos textiles, tejedoras y público en general. A la par de la exposición, dimos talleres de "Tejido y Memoria", y organizamos una muestra audiovisual con dicha temática.

A lo largo del recorrido, mi cámara acompañó todo el proceso. El documental logra rescatar aquellos momentos de mayor sensibilidad y empatía con los espectadores y participantes de los talleres. La intención principal fue retribuir la confianza y el esfuerzo de las tejedoras colombianas al enviarnos sus piezas tejidas y compartirnos sus historias tan profundamente dolorosas. A través del video pudieron apreciar el impacto y la resonancia que tuvo la exposición para las tejedoras mexicanas y la sociedad civil en general que tuvieron la oportunidad de asistir a la exposición o participar en los talleres.

Al finalizar los tres meses de recorrido por México con la exposición, habíamos tejido ya muchos lazos y redes entre personas. El documental, a manera de hilo conductor, relata y muestra la respuesta de la gente a la exposición y describe el trabajo de cada uno de los colectivos que visitamos. También reflexiona sobre los puentes que se tejen entre la creación colectiva, la creatividad y la expresión como formas que permiten sanar y potenciar el carácter transformador que tienen los espacios para crear, narrar y tejer. 
De alguna forma, este documental es una suerte de resumen o síntesis de la investigación doctoral donde se reúnen diversas experiencias en torno al textil y el acto de tejer. Fue el medio y soporte que transportó mensajes entre tejedoras y en general es un retrato de las múltiples apropiaciones posibles que pueden generarse alrededor del tejido.

La realización de los cinco videos documentales significó más que un refugio para no perderme entre las historias de otras tejedoras, fue la oportunidad de experimentar, ejercitar la mirada, desarrollar un estilo propio para tejer con imágenes mi recorrido en este andar etnográfico. Culminé la investigación con un tejido de imágenes que dan cuenta de la experiencia vivida en el encuentro intercultural donde convergieron diversas subjetividades y vivencias alrededor del tejido.

A continuación, comparto las ligas a los otros cuatro documentales que acompañan la investigación y que permitirán una mayor comprensión del trasfondo que el tejido tiene como principio liberador, sanador, concientizador y transformador.

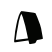

\section{FICHA TÉCNICA}

Directora: Mariana Rivera

Año: 2015

Duración: 20 minutos

País: México

Formato: HD

Diseño Sonoro: Josué Vergara

Música: Natalia Magliano y Leticia Servín

Link para el vídeo:

https://vimeo.com/151735928

Otros vídeos

Tejer para no olvidar https:/ / vimeo.com/58517165

Escribiendo sobre el telar https:/ / vimeo.com/109621801

Telares Sonoros https://vimeo.com/98899180

La Flor de Xochistlahuaca https:/ / vimeo.com/158946012 
Mariana Xochiquétzal Rivera García es doctora en Ciencias Antropológicas por la UAM-I y maestra en Antropología Visual por la FLACSO-Ecuador. Actualmente es investigadora de la Dirección de Etnología y Antropología Social del INAH y se desempeña como documentalista y fotógrafa independiente. Trabaja en torno a la antropología visual temas como la memoria, el cine documental y etnográfico, y más recientemente sobre narrativas transmedia. Es autora de diversos artículos especializados en antropología visual, así como de ensayos fotográficos. También es realizadora de los documentales Sueños de Mayo (2011), Escribiendo sobre el telar (2013), Telares Sonoros (2014), Nos pintamos solas (2014), El hilo de la memoria (2016), Huellas para la memoria (2016), y su más reciente largometraje documental Se va la vida, compañera (2018) proyecto realizado con el estímulo DOCTV Latinoamérica en su vi edición. También destacan sus cortometrajes documentales musicales, así como videoclips bajo el sello de la casa productora Urdimbre Audiovisual. 
Ángela Renée de la Torre Castellanos

Directora de Encartes antropológicos

Arthur Temporal Ventura

Editor

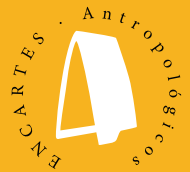

Verónica Segovia González

Diseño y formación

Cecilia Palomar Verea

María Palomar Verea

Corrección

Saúl Justino Prieto Mendoza

Difusión

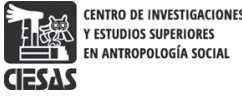

Encartes cuenta con el apoyo de El Colegio de la Frontera Norte.

Equipo de coordinación editorial

Renée de la Torre Castellanos Directora de Encartes antropológicos - María Eugenia de la O Martínez CIESAS -Occidente - Joel Pedraza Mandujano CIESAS -Occidente - Santiago Bastos Amigo CIESAS -Occidente Manuela Camus Bergareche Universidad de Guadalajara - Alejandra Navarro Smith ITESO - Luis Escala Rabadán El COLEF

\section{Comité editorial}

Agustín Escobar Latapí Director general de CIESAS - Alberto Hernández Hernández Presidente de El colef Andrés Fábregas Puig CIESAS -Occidente - Dulce Mariana Gómez Salinas Subdirectora del departamento de publicaciones de CIESAS - Érika Moreno Páez Coordinadora del departamento de publicaciones de El colef José Manuel Valenzuela Arce El colef - Luz María Mohar Betancourt CIESAS -Ciudad de México - Ricardo Pérez Monfort CIESAS -Ciudad de México - Sévérine Durin Popy CIESAS -Noreste C Carlos Yuri Flores Arenales Universidad Autónoma del Estado de Morelos - Sarah Corona Berkin DECS /Universidad de Guadalajara Norma Iglesias Prieto San Diego State University - Camilo Contreras Delgado El colef

Cuerpo académico asesor

Alejandro Frigerio

Universidad Católica

Argentina-Buenos Aires

Alejandro Grimson

USAM -Buenos Aires

Alexandrine Boudreault-Fournier

University of Victoria-Victoria

Carlo A. Cubero

Tallinn University-Tallin

Carlo Fausto

UfRJ -Rio de Janeiro

Carmen Guarini

UBA -Buenos Aires

Caroline Perré

Centro de Estudios Mexicanos y

Centroamericanos-Ciudad de

México

Clarice Ehlers Peixoto

UERJ -Rio de Janeiro

.

\author{
Julia Tuñón \\ INAH -Ciudad de México \\ María de Lourdes Beldi \\ de Alcantara \\ USP-Sao Paulo \\ Mary Louise Pratt \\ NYU -Nueva York \\ Pablo Federico Semán \\ CONICET / UnSAm -Buenos Aires \\ Renato Rosaldo \\ NYU -Nueva York \\ Rose Satiko Gitirana Hikji \\ USP -Sao Paulo \\ Rossana Reguillo Cruz \\ ITESO -Guadalajara \\ Sarah Pink \\ RMIT -Melbourne
}

ENCARTES antropológicos, año 1, núm 2, septiembre 2018-marzo 2019, es una revista académica digital de acceso libre y publicación semestral editada por el Centro de Investigaciones y Estudios Superiores en Antropología Social, calle Juárez, núm. 87, Col. Tlalpan, C. P. 14000, México, D. F., Apdo. Postal 22-048, Tel. 548735 70, Fax 565555 76, encartesantropologicos@ciesas.edu.mx. Directora de la revista: Ángela Renée de la Torre Castellanos. Alojada en la dirección electrónica http://www.encartesantropologicos.mx. ISSN : 2594-2999. Las opiniones expresadas por los autores no necesariamente reflejan la postura de la revista. Se autoriza la reproducción parcial de los materiales publicados siempre y cuando se haga con fines estrictamente no comerciales y se cite la fuente. Salvo excepciones explicitadas, todo el contenido de la publicación está bajo una Licencia Creative Commons Atribución-NoComercial 4.0 Internacional. 